\section{DISCUSSION}

Nafamostat mesilate has been used as an anticoagulant in substitution for heparin in the situations of $\mathrm{CPB}$, left ventricular assist devices, and hemodialysis. The main advantages of nafamostat mesilate are its short half-life and its functioning to inactivate coagulation, fibrinolysis, and platelet aggregation. Murase and colleagues ${ }^{8}$ demonstrated that nafamostat mesilate inhibits fibrinolysis, preserves platelet function during $\mathrm{CPB}$, and reduces blood loss. Ota and associates ${ }^{9}$ demonstrated successful CPB management with mesilate for 3 patients with recent intracranial hemorrhage. Both groups emphasized that inhibition of fibrinolysis activation was the most important supplementary effect of nafamostat mesilate, because as excessive fibrinolysis can cause intracranial bleeding during and after $\mathrm{CPB} .{ }^{8,9}$ On the other hand, heparin enhances fibrinolytic activity during $\mathrm{CPB}$, leading to dissolution of clots and recurrence of bleeding. In this study we demonstrated successful CPB management with a continuous infusion of nafamostat mesilate in open heart surgical procedures for patients after acute stroke.

Some authors have maintained that low-dose heparin can achieve adequate anticoagulation during $\mathrm{CPB}$, but Ovrum and coworkers ${ }^{2}$ reported that clot formation in the cardiotomy reservoir occurred during $\mathrm{CPB}$ with lowdose heparin. In our opinion, low-dose heparinization during CPB should not be routinely used because of the risk of clot formation; however, it provides an advantage for patients with the risk of bleeding. We believe that the combination of low-dose heparin and nafamostat mesilate can produce safer anticoagulation than can lowdose heparin.

Limitations to the current study include small sample size, the lack of a control group, the lack of data on fibrinolysis, and the study's retrospective nature. Further prospective analysis is needed to confirm the advantage of our CPB strategy with low-dose heparin and nafamostat mesilate for patients with bleeding risks.

\section{References}

1. Eishi K, Kawazoe K, Kuriyama Y, Kitoh Y, Kawashima Y, Omae T. Surgical management of infective endocarditis associated with cerebral complications: Multicenter retrospective study in Japan. J Thorac Cardiovasc Surg. 1995;110:1745-55.

2. Ovrum E, Tangen G, Tollofsrud S, Oystese R, Ringdal MA, Istad R. Comparison of two heparin-coated extracorporeal circuit with reduced systemic anticoagulation in routine coronary artery bypass surgery. J Thorac Cardiovasc Surg. 2001;121:324-30.

3. Aoyama T, Ino Y, Ozeki M, et al. Pharmacological studies of FUT-175, nafamostat mesilate. I. Inhibition of protease activity in in vitro and in vivo experiments. Jpn J Pharmacol. 1984;35:203-27.

4. Okajima K, Uchiba M, Murakami K. Nafamostat mesilate. Cardiovasc Drug Rev. 1995; 13:51-65

5. Yang JW, Han BG, Kim BR, Lee YH, Kim YS, Yu JM, Choi SO. Superior outcome of nafamostat mesilate as an anticoagulant in patients undergoing maintenance hemodialysis with intracerebral hemorrhage. Ren Fail. 2009;31:668-75.

6. Kotani K, Ichiba S, Andou M, Sano Y, Date H, Tedoriya T, et al. Extracorporeal membrane oxygenation with nafamostat mesilate as an anticoagulant for massive pulmonary hemorrhage after living-donor lobar lung transplantation. J Thorac Cardiovasc Surg. 2002;124:626-7.

7. Despotis GJ, Gravlee G, Filos K, Levy J. Anticoagulation monitoring during cardiac surgery: a review of current and emerging techniques. Anesthesiology. 1999; 91:1122-51.

8. Murase M, Ushi A, Tomita Y, Maeda M, Koyama T, Abe T. Nafamostat mesilate reduces blood loss during open heart surgery. Circulation. 1993;88(5 Pt 2):II432-6.

9. Ota T, Okada K, Kano H, Okita Y. Cardiopulmonary bypass using nafamostat mesilate for patients with infective endocarditis and recent intracranial hemorrhage. Interact Cardiovasc Thorac Surg. 2007;6:270-3.

\title{
Transcatheter aortic valve implantation combined with conventional heart surgery: Hybrid approach for complex cardiac pathologic features
}

\author{
Miralem Pasic, MD, PhD, Semih Buz, MD, Axel Unbehaun, MD, and Roland Hetzer, MD, PhD, Berlin, \\ Germany
}

A new hybrid approach, the combination of transcatheter aortic valve implantation (TAVI) and conventional cardiac

\footnotetext{
From the Department of Cardiovascular Surgery, Himeji Cardiovascular Center, Himeji, Japan

Disclosures: Drs Pasic, Unbehaun, and Buz have been proctors to Edwards Lifesciences since July 2009. All other authors have nothing to disclose with regard to commercial support.

Received for publication Feb 1, 2012; revisions received March 13, 2012; accepted for publication March 19, 2012; available ahead of print April 16, 2012.

Address for reprints: Miralem Pasic, MD, PhD, Deutsches Herzzentrum Berlin, Augustenburger Platz 1, Berlin 13353, Germany (E-mail: pasic@dhzb.de).

J Thorac Cardiovasc Surg 2012;144:728-31

$0022-5223 / \$ 36.00$

Copyright (c) 2012 by The American Association for Thoracic Surgery

http://dx.doi.org/10.1016/j.jtcvs.2012.03.056
}

surgery, might be a possible solution for patients considered not suitable for complex conventional surgery. We have summarized our preliminary experience. ${ }^{1-3}$

\section{BRIEF CLINICAL REPORT}

From April 2008 to October 2011, 11 patients underwent simultaneous conventional cardiac surgery and TAVI with or without additional percutaneous coronary intervention (PCI) (Table 1). Ten patients had severe aortic valve stenosis, and one (patient 11) had pure insufficiency. The combined procedure was the first heart operation in 6 patients, the second in 3 patients, the third in 1 patient, and the fourth in 1 patient. 
TABLE 1. Patient and procedural parameters

\begin{tabular}{|c|c|c|c|c|c|c|c|c|c|}
\hline $\begin{array}{l}\text { Pt. } \\
\text { no. }\end{array}$ & $\begin{array}{c}\text { Age } \\
(y)\end{array}$ & $\begin{array}{c}\text { EuroSCORE } \\
(\%)\end{array}$ & $\begin{array}{c}\text { STS score } \\
(\%)\end{array}$ & $\begin{array}{c}\text { LVEF } \\
(\%)\end{array}$ & $\begin{array}{l}\text { Main reason for } \\
\text { hybrid procedure }\end{array}$ & $\begin{array}{c}\text { Surgery type } \\
\text { combined with TAVI }\end{array}$ & $\begin{array}{l}\text { CPB time } \\
(\min )\end{array}$ & $\begin{array}{l}\text { Crossclamp time } \\
(\text { min) }\end{array}$ & $\begin{array}{c}\text { Median } \\
\text { sternotomy }\end{array}$ \\
\hline 1 & 72 & 50.8 & 21.4 & 30 & Comorbidities & LV aneurysmectomy & 0 & 0 & No (redo) \\
\hline 2 & 69 & 26.9 & 5.9 & 20 & Porcelain aorta & CABG (LITA to LAD) & 0 & 0 & Yes \\
\hline 3 & 62 & 46.3 & 18.5 & 35 & Comorbidities & LV aneurysmectomy & 0 & 0 & No (redo) \\
\hline 4 & 70 & 50.2 & 12.9 & 50 & Shock & Tricuspid valve repair & 123 & 0 & No (redo) \\
\hline 5 & 86 & 79.5 & 28.9 & 60 & Porcelain aorta & Tricuspid valve repair & 150 & 0 & Yes \\
\hline 6 & 85 & 42.8 & 10.7 & 50 & Frailty & LV aneurysmectomy & 0 & 0 & No \\
\hline 7 & 89 & 53.9 & 24.1 & 35 & Frailty & $\begin{array}{c}\text { Tricuspid valve replacement, } \\
\text { CABG (SVG to RCA) }\end{array}$ & 172 & 0 & Yes \\
\hline 8 & 84 & 84.9 & 22.9 & 20 & Myocardial failure & $\begin{array}{l}\text { CABG (LITA to LAD), PCI } \\
\text { (CX and RCA) }\end{array}$ & 0 & 0 & Yes \\
\hline 9 & 43 & 57.9 & 8.7 & 35 & Porcelain aorta & Mitral valve replacement & 77 & 0 & Yes (second redo) \\
\hline 10 & 93 & 28.5 & 13.8 & 55 & Frailty & $\begin{array}{l}\text { LV aneurysmectomy, PCI } \\
\text { (LAD and CX) }\end{array}$ & 0 & 0 & No \\
\hline 11 & 40 & 19.4 & 3.3 & 55 & Porcelain aorta & Redo-CABG (LITA to LAD) & 131 & 60 & Yes (third redo) \\
\hline
\end{tabular}

Pt. no., Patient number; EuroSCORE, European System for Cardiac Operative Risk Evaluation; STS, Society of Thoracic Surgeons; $L V E F$, left ventricular ejection fraction; TAVI, transcatheter aortic valve implantation; $C P B$, cardiopulmonary bypass; $L V$, left ventricular; $C A B G$, coronary artery bypass grafting; $L I T A$, left internal thoracic artery; $L A D$, left anterior descending (coronary artery); $S V G$, saphenous vein graft; $R C A$, right coronary artery; $P C I$, percutaneous coronary intervention; $C X$, circumflex coronary artery.
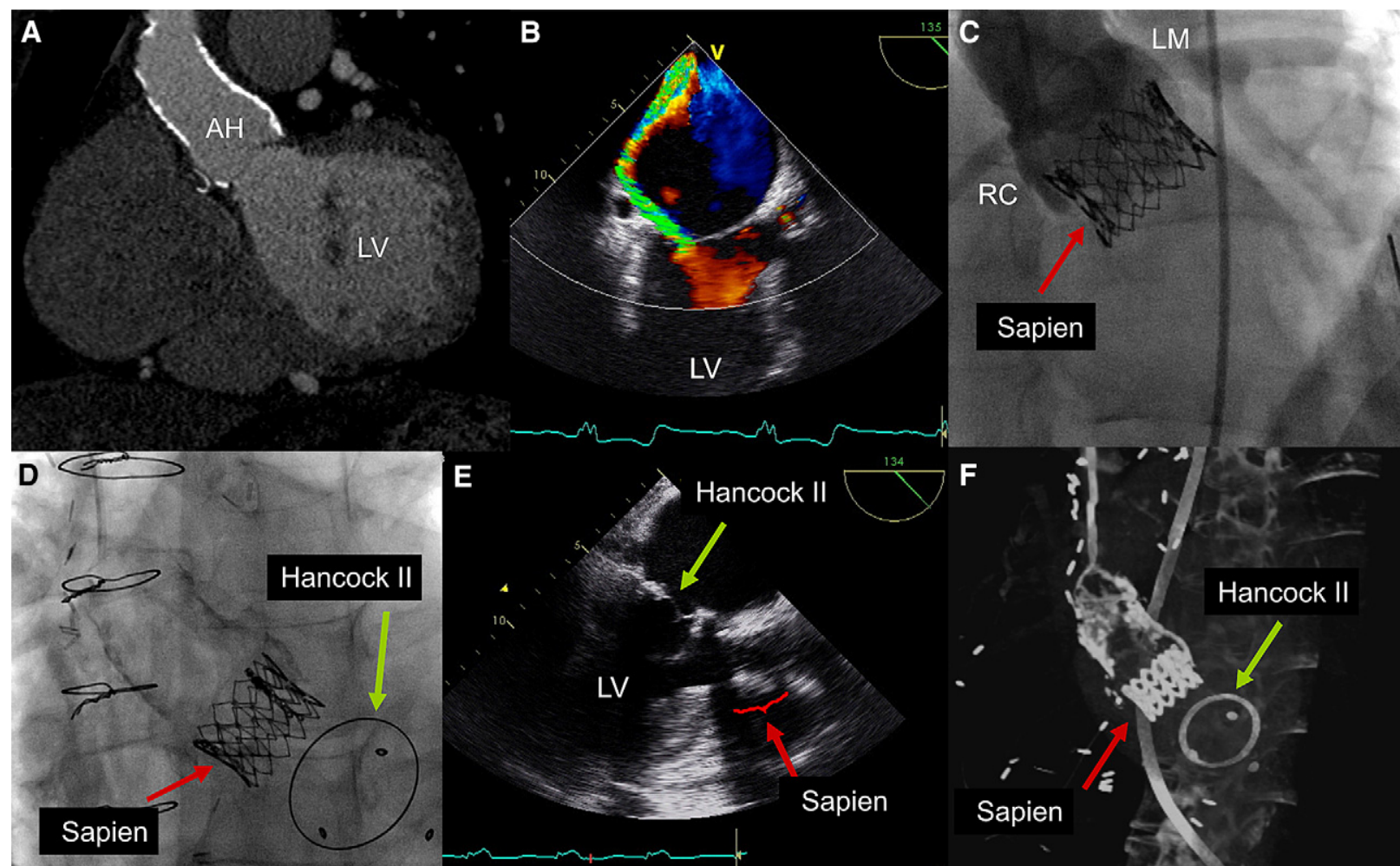

FIGURE 1. "Valve-in-homograft" transapical aortic valve implantation (TAVI) combined with mitral valve replacement on the beating heart. Patient 9 with homograft degeneration in the aortic position ("porcelain aorta") (A) and severe mitral valve regurgitation (B). Angiography confirmed optimal "valve-in-homograft" position of the transcatheter aortic valve prosthesis without any paravalvular leakage (C). Fluoroscopy (D), transesophageal echocardiography (E), and computed tomography (F) showing both newly implanted prostheses. The patient's risk profile was extremely high owing to his preoperative condition, including asthenia secondary to congestive heart failure, chronic obstructive pulmonary disease, pulmonary hypertension ( $95 / 65 \mathrm{~mm}$ $\mathrm{Hg}$ ), liver cirrhosis, portal hypertension, ascites, a previous splenorenal shunt, a history of bleeding from esophageal varices, and chronic anemia. His medical history included a diagnosis of Marfan syndrome, composite graft replacement of the ascending aorta and aortic valve for type A dissection 12 years previously, and redo surgery for prosthetic valve endocarditis with aortic annular abscess treated with aortic homograft implantation 6 years previously. AH, Aortic homograft; $R C$, right coronary artery; $L M$, left main coronary artery; $L V$, left ventricle. 
The surgical access for the combined procedures was either standard median sternotomy (6 patients) or left anterior minithoracotomy (4 patients; Table 1$)$. One patient (patient 4) with previous cardiac surgery underwent TAVI through a left anterior minithoracotomy and additional tricuspid valve repair through a right anterior thoracotomy.

TAVI was combined with mitral valve replacement in 1 patient (Figure 1), tricuspid valve repair in 2, tricuspid valve replacement and coronary artery bypass grafting $(\mathrm{CABG})$ in 1 , left ventricular aneurysmectomy in 3 , left ventricular aneurysmectomy and PCI in $1, \mathrm{CABG}$ in 1 , redo $\mathrm{CABG}$ in 1, and CABG and PCI in 1. Normothermic cardiopulmonary bypass $(\mathrm{CPB})$ was used in 5 patients with aortic crossclamping in only 1 (crossclamp time, 60 minutes). The mean CPB time was $120 \pm 31$ minutes (range, 77-172 minutes; Table 1). The median procedural time ("skin-toskin") was 266 minutes (interquartile range, 155-395 minutes). Transapical TAVI $^{4,5}$ with balloon-expandable valves (Edwards Sapien THV; Edwards Lifesciences, Irvine, Calif) was performed in 10 patients and open, direct transaortic repeat $\mathrm{TAVI}^{6}$ in 1 (patient 11) for technical surgical reasons after previous "valve in valve" TAVI in a degenerated homograft. If median sternotomy was used for the combined procedure, the transapical TAVI procedure was slightly modified with regard to the placement of the $14 \mathrm{~F}$ and $26 \mathrm{~F}$ introducers. They were forwarded through a 1-cm incision below the left costal arch into the pericardium toward the apex and then through the apex into the left ventricular cavity. ${ }^{1}$ This approach enabled us to leave the enlarged heart in situ without the need to mobilize it. Additionally, access to the aortic valve is direct and without any need for curving or angulation of the axis from the apex to the ascending aorta. Otherwise, because of the rigid introducers, the heart would have had to be mobilized and displaced from the pericardium. ${ }^{1}$ Coronary artery disease, if present, was treated simultaneously by CABG or PCI. ${ }^{2}$ If used, $\mathrm{PCI}$ was performed as the last procedure using transfemoral access. ${ }^{2}$

The technical success of the combined procedures was $100 \%$, with no intraoperative mortality or procedural complications. Also, no 30-day mortality or in-hospital mortality occurred. Of the 11 patients, 7 had an uneventful postoperative course and 4 developed postoperative complications. The mean follow-up was $14 \pm 12$ months. All patients improved, with all patients in New York Heart Association functional class I to II. No paravalvular leakage developed during follow-up and no new neurologic events occurred. During the follow-up period, 1 patient (patient 8) developed prosthetic valve endocarditis 3 months after TAVI that was successfully treated with antibiotics. Three noncardiac-related deaths occurred (patients 1, 5, and 7 at
7,10 , and 2 months postoperatively, respectively), for overall follow-up survival of $73 \%$.

\section{DISCUSSION}

Our preliminary results from an extremely heterogeneous group of patients showed that a combined procedure (TAVI with standard cardiac surgery) is possible and safe. Replacing conventional aortic valve surgery with TAVI in a complex surgical procedure might enable the treatment of patients who would otherwise not be eligible for complex conventional surgery. Depending on the type of surgical procedure, the hybrid approach could shorten or eliminate aortic crossclamping or even waive the need for CPB. The avoidance of aortic crossclamping (or keeping the aortic crossclamp time as short as possible) precludes or reduces global myocardial ischemia in serious conditions. The hybrid approach avoids extensive surgical dissection in patients with previous cardiovascular procedures. Therefore, the combined approach offers easier intraoperative management and faster postoperative recovery of the patients. This hybrid concept using a transcatheter biologic prosthetic valve could be applied in younger polymorbid patients with a reduced life expectancy (eg, patient 9) or patients who choose a biologic valve because of their occupational requirements or a private lifestyle with possible detrimental effects of anticoagulant therapy (eg, patient 11). In the future, if the prosthetic valve degenerates, the "valve-in-valve" concept using simple repeat TAVI performed using either the transfemoral or transapical approach-an easy technical procedure-could be applied (with no additional risk if prospective definitive surgery should be needed).

The new hybrid approach and the unification of the surgical way of thinking with the experience of interventional cardiologists opens up a new treatment strategy for very high-risk patients with complex cardiac problems. It can be expected that in the future these new types of hybrid procedures will be more frequently applied for complex pathologic features of the heart or redo surgery.

The other members of our TAVI team were Thorsten Drews, MD, Stephan Dreysse, MD, Giuseppe D'Ancona, MD, PhD, Marian Kukucka, MD, Alexander Mladenow, MD, Guna Tetere, MD, Tom Gromann, MD, Ekatarina Ivanitskaia-Kühn, MD, Christoph Klein, MD, Katrin Schäfer, and Natalia Solowjowa, MD. We thank Anne Gale for editorial assistance and Rosemarie Günther for secretarial help.

\section{References}

1. Pasic M, Unbehaun A, Buz S, Drews T, Hetzer R. Transapical aortic valve implantation and "off-pump" arterial coronary bypass in a patient with porcelain aorta. J Heart Valve Dis. 2011;20:711-4.

2. Pasic M, Dreysse S, Unbehaun A, Buz S, Drews T, Klein C, et al. Combined elective percutaneous coronary intervention and transapical 
transcatheter aortic valve implantation. Interact Cardiovasc Thorac Surg. 2012; $14: 485-7$

3. Unbehaun A, Pasic M, Dreysse S, Buz S, Kukucka M, Hetzer R, Drews T. Transcatheter aortic valve implantation and hybrid coronary artery revascularizationtime to combine them. Innovations. 2011;6:395-8.

4. Walther T, Dewey T, Borger MA, Kempfert J, Linke A, Becht R, et al. Transapical aortic valve implantation: step by step. Ann Thorac Surg. 2009;87:276-83.
5. Pasic M, Dreysse S, Drews T, Buz S, Unbehaun A, Kukucka M, et al. Improved technique of transapical aortic valve implantation: "the Berlin addition" Ann Thorac Surg. 2010;89:2058-60.

6. Olsen LK, Arendrup H, Engstrom T, Sondergard L. When operable patients become inoperable: conversion of a surgical aortic valve replacement into transcatheter aortic valve implantation. Interact Cardiovasc Thorac Surg. 2009;9: $837-9$.

\title{
Warm beating heart with deep hypothermic circulatory arrest: A technique for an unclampable aorta with aortic valve regurgitation
}

\author{
Zain Khalpey, MD, PhD, MRCS, ${ }^{\text {a,b }}$ Rene J. Dekkers, CCP, ${ }^{\text {a,b }}$ Foeke J. H. Nauta, MD, ${ }^{\text {a,b }}$ and \\ Prem Shekar, MD, ${ }^{\mathrm{a}, \mathrm{b}}$ Boston, Mass
}

The presence of severe aortic insufficiency (AI) in patients with severe atherosclerotic disease of the ascending aorta at aortic valve replacement (AVR) poses considerable technical challenges, often associated with poor outcomes. $^{1,2}$ Furthermore, the risk of cerebral embolus precludes the use of an aortic crossclamp. ${ }^{1}$ The use of deep hypothermic circulatory arrest increases overall safety; however, it is associated with an increased risk of neurologic complications. ${ }^{3}$

We report a technique applied to 2 patients in which the heart was kept warm and beating in normal sinus rhythm while systemically cooling the body and organs. This strategy attempts to eliminate the ventricular fibrillation associated with hypothermia, avoiding left ventricular distension and endocardial ischemia, without clamping the aorta.

\section{METHODS}

After systemic heparinization, we cannulated the right axillary artery with an 8-mm Hemashield graft (Boston Scientific, Boston, Mass), connected to a $3 / 8 \times 3 / 8$ straight connector (Sorin Group, Arvada, Colo). Venous cannulation consisted of a $21 \mathrm{~F} 60-\mathrm{cm}$ Biomedicus (Medtronic, Minneapolis, Minn) femoral venous cannula placed percutanously into the right femoral vein and a single-stage malleable cannula placed into the superior vena cava (Medtronic). Cardiopulmonary bypass (CPB) was initiated. To prevent distension, both patients had a vent placed in the right superior pulmonary vein just after initiating $\mathrm{CPB}$ and before systemic cooling began. A retrograde coronary sinus cannula, either the Gundry

\footnotetext{
From the Deutsches Herzzentrum Berlin, Berlin, Germany.

Disclosures: Authors have nothing to disclose with regard to commercial support.

Z.K. and R.J.D. contributed equally to this work.

Received for publication Jan 19, 2012; revisions received March 9, 2012; accepted for publication March 19, 2012; available ahead of print April 16, 2012.

Address for reprints: Zain Khalpey, MD, PhD, MRCS, Department of Cardiac Surgery, Brigham and Women's Hospital, Harvard Medical School, 75 Francis St,

Boston, MA 02115 (E-mail: zkhalpey@partners.org).

J Thorac Cardiovasc Surg 2012;144:731-2

$0022-5223 / \$ 36.00$

Copyright (c) 2012 by The American Association for Thoracic Surgery

http://dx.doi.org/10.1016/j.jtcvs.2012.03.057
}

retrograde cannula (Medtronic) or the Edwards Life Science RC 2014 (Edwards Life Science, Irvine, Calif) was placed into the coronary sinus directly with echocardiographic assistance. The Sorin BCD Vanguard cardioplegia system (Sorin Group) was used to administer warm $\left(37^{\circ} \mathrm{C}\right)$ pump blood at $300 \mathrm{~mL} / \mathrm{min}$ into the coronary sinus. The retrograde circuit pressures reached $175 \mathrm{~mm} \mathrm{Hg}$, and coronary sinus pressures of 30 to $40 \mathrm{~mm}$ $\mathrm{Hg}$ were maintained while the patients were being cooled.

Systemic cooling with a $10^{\circ}$ to $12^{\circ} \mathrm{C}$ gradient to $22^{\circ}$ to $20^{\circ} \mathrm{C}$ was initiated with the Maquet Heater-Cooler Unit HCU 30 Dual Heater Cooler (MAQUET Cardiovascular, Wayne, NJ).

Below arterial $32^{\circ} \mathrm{C}$, an effort was made to safely decrease the CPB flow and thus the circuit line pressure, decreasing the incidence of competitive cold antegrade blood from the CPB in-flow cannula.

When the patient venous line and nasopharyngeal temperatures equalized at $22^{\circ} \mathrm{C}$ to $20^{\circ} \mathrm{C}, 30 \mathrm{mM}$ of systemic potassium was administered into the CPB pump to arrest the heart. The heart rate before potassium administration was bradycardic (22-30 beats/min), normal sinus rhythm Cold blood cardioplegia was administered to arrest the heart for the rest of the operation in an antegrade or retrograde route as per standard techniques.

\section{RESULTS}

Both patients underwent successful AVR and replacement of the ascending aorta. The duration of sinus bradycardia until cardiac arrest (ie, time of systemic cooling) was 60 and 65 minutes followed by potassium administration at $22.4^{\circ} \mathrm{C}$ at $20.0^{\circ} \mathrm{C}$, respectively. There was no operative mortality, and postoperatively, the patients showed no signs of neurologic sequelae.

\section{DISCUSSION}

This technique can be considered an alternative for patients in who aortic crossclamping is unsafe and might otherwise be inoperable.

Constant coronary perfusion, particularly in patients with hypertrophied ventricles, ${ }^{4}$ while maintaining sinus rhythm and cardiac contractions is crucial for optimal myocardial protection. $^{5}$ 